\title{
Um golpe de mestre: crianças e pais frente ao diagnóstico psiquiátrico
}

\author{
Karla Patrícia Holanda Martins*! \\ Raquel Alencar Barreira Rolim*2 \\ Gabriela Monteiro Simão*3 \\ Paulo Alves Parente Junior*4
}

O presente trabalho provém de reflexões advindas de escuta $e$ intervenção em um grupo de pais, realizado em um ambulatório público de psiquiatria. A dicotomia dos efeitos da nomeação diagnóstica se apresenta ora permitindo inscrever a criança e o adolescente numa ordem de filiação, ora produzindo um engessamento das possibilidades de subjetivação. Problematizam-se as formas de filiação construídas sob o caráter prescritivo do diagnóstico psiquiátrico e seus possíveis efeitos nos modos de cuidado e nos laços estabelecidos entre pais e filhos.

Palavras-chave: Diagnóstico, nomeação, filiação, psicanálise com crianças

\footnotetext{
*1,2 Universidade Federal do Ceará - UFC (Fortaleza, CE, Br).

*3,4 Mestrandos na Universidade Federal do Ceará - UFC (Fortaleza, CE, Br).
} 


\section{ARTIGOS}

\section{Introdução}

A discussão sobre o diagnóstico psiquiátrico dado aos pacientes não está alheia às preocupações da psicanálise. Da "Moral sexual civilizada..." (1908/1996b) ao "Mal-estar na civilização" (1930/1996d), a perspectiva do diagnóstico na obra freudiana é incapaz de isolar o sofrimento de sua imbricação com o mundo a que estamos inarredavelmente imersos. Não recai sobre a infelicidade apenas o peso da desadaptação ou inadequação dos indivíduos à norma cultural, sendo a própria civilização responsável pela hostilidade destes aos códigos civilizatórios.

Quando o sofrimento possui um discurso social que o ampara na cultura, ele encontra um lugar de reconhecimento. O mal-estar é o que resiste inominável, isolado em um mundo sem entranhas. $\mathrm{O}$ sem-lugar também, no entanto, é o que nos aponta para a imperiosa luta pelo reconhecimento quando ainda não há nome nem lugar para o desejo e a angústia. A clínica psicanalítica não é a única que trabalha com o mal-estar, assim como com a transferência, mas é uma das poucas formas de manejo que os correlaciona ao desejo e à angústia. Em contraste, é expresso, atualmente, um avançado esgotamento das abordagens clínicas como resultado da inflação dos diagnósticos nosológicos que estão embasando a prescrição de medicamentos e modos de conduta. É a era das fabricações diagnósticas que se antecipam às doenças, elevando alguns traços de caráter ou excessos comportamentais ao status de transtornos definidos com base em seus tratamentos medicamentosos (Porge, 2015).

Nesse ínterim, os quadros clínicos - descritos em diagnósticos, consideravam a subjetividade do paciente elemento fundamental para o entendimento de sua conduta - foram desaparecendo 
ao longo das versões do DSM, como aponta Dunker (2015). Esse fato representa muito mais do que uma mudança de paradigma teórico. Na verdade, negando abertamente o estudo etiológico, o procedimento enquadra os múltiplos sintomas em uma nosografia predefinida.

Simultaneamente, o discurso acerca da saúde mental, antes restrito ao âmbito médico e científico, passa a ser dependente das relações de mercado e se expande para outros domínios da cultura, alcançando o universo das relações familiares e o âmbito das práticas pedagógicas. Com efeito, como observa Travaglia (2014) em diálogo com as considerações de outros psicanalistas (Coriat, 2011), as "convocatórias medicalizantes" funcionam como um discurso social que atrai narrativas de sofrimento; ou seja, ofertam significantes que, se por um lado podem apaziguar sintomas, de outra parte são passíveis de aprofundar o sofrimento psíquico.

É tendo por base essa configuração de "medicalização" do sofrimento e desvalorização da escuta do sujeito que este artigo estabelece seu ponto de partida. Objetiva, portanto, refletir sobre os efeitos da hegemonia dos discursos dos especialistas médicos - pedopsiquiatras e neuropediatras sobre o estabelecimento de modalidades de filiação e de cuidado no âmbito das relações parentais, com suporte numa experiência em um serviço ambulatorial de hospital mental que atende crianças e adolescentes. Mais especificamente, este texto analisa os possíveis efeitos da "medicalização" na infância sobre a operação de filiação, considerando que aquela incide sobre as relações entre pais e filhos, influenciando, sobretudo, naquilo que é esperado e proposto às crianças e aos jovens. A leitura interpretativa deste percurso baseia-se nas indicações de Freud e Lacan, fundamentais para se pensar a função da nomeação e seus efeitos sobre a filiação, tensionando-as com o diagnóstico psiquiátrico.

Desde já, ressalta-se a sucessiva referência das mães à sua gratidão ao serviço, quando narram as suas experiências de "finalmente" haverem encontrado "alguém" capaz de compreendê-las e nomear o seu sofrimento e de seus filhos. Há um antes e um depois do diagnóstico, entendido como um ponto

\footnotetext{
1 "Entende-se por medicalização o processo por meio do qual as questões da vida social complexas, multifatoriais e marcadas pela cultura e pelo tempo histórico - são reduzidas a um tipo de racionalidade que vincula artificialmente a dificuldade de adaptação às normas sociais a determinismos orgânicos que se expressariam no adoecimento do indivíduo" (Fórum Sobre Medicalização da Educação e Saúde, 2015, p. 11).
} 


\section{ARTIGOS}

de transformação e criação de sentidos para suas vidas. Chama atenção, nesse modo de percepção, a que ponto um quadro dotado de classificações psicopatológicas pode lastrear as palavras dos pais e incidir tão radicalmente nas expectativas e na elaboração de modalidades de endereçamento aos filhos.

O contraste entre a perspectiva psicanalítica e a abordagem médico-diagnóstica sublinha as "convocatórias desejantes" (Coriat, 2011, p. 173) em jogo nas parentalidades, ressaltando a influência do laudo psiquiátrico sobre os laços de filiação, proposições clínicas que "anulam a possibilidade de surgimento de um sujeito do desejo". Nesse contexto, Travaglia (2014) aponta para a existência de "convocatórias medicalizantes" p. 43), fundadas no discurso médico-científico e capazes de ocupar o lugar do Outro no imaginário social, produzindo efeitos de exclusão e negativação de uma dimensão subjetiva dos pacientes. Justifica-se assim a importância de se interrogar sobre os outros possíveis aspectos de subjetividade produzidos nesse laço com os saberes médicos.

Os dois anos de trabalho clínico junto ao grupo de pais e familiares, à brinquedoteca e às reuniões de equipe forneceram elementos para pensarmos sobre o lugar que ocupa o diagnóstico nas relações de filiação. As sessões realizadas com o Grupo de Pais do serviço representam subsídios para discutirmos a hipótese de que o diagnóstico influencia na ressignificação dos liames da filiação, podendo formatar modos distintos de demanda parental.

\section{Um grupo para pais e acompanhantes/cuidadores}

A demanda pelo grupo com os pais foi formulada pelos psicólogos da equipe do ambulatório e começou a ser desenvolvida por estagiários do Departamento de Psicologia da Universidade Federal do Ceará, acompanhados inicialmente por uma psicopedagoga e, em seguida, por uma psicóloga do serviço. No segundo ano de trabalho, o grupo passou também a contar com a coordenação de uma psicanalista e pesquisadora do Programa de Pós-Graduação do mesmo Departamento. ${ }^{2}$

Os participantes não eram os mesmos todas as semanas, pois os familiares frequentavam o grupo quando iam às consultas médicas, quinzenal ou mensalmente. Além disso, esses transitavam, não permanecendo,

\section{${ }^{2}$ Bolsista DCR CNPq/ FUNCAP.}




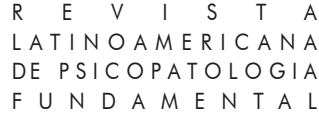

necessariamente, do início ao final do horário previsto. O Grupo se reunia, semanalmente (uma hora, em média), antes da consulta com os médicos. A aposta feita era a de que o Grupo de Pais deveria se constituir como um dispositivo, mais do que um local de encontro, que haveria de possibilitar a circulação e o entrecruzamento dos discursos, objetivando favorecer o deslocamento de posições subjetivas já constituídas e fixadas dos participantes. Contudo, observa-se que as discussões ganhavam força quando surgiam depoimentos sobre o 'sucesso' dos medicamentos. Nessas ocasiões, os participantes queriam saber o diagnóstico, a posologia do medicamento e o tempo de estabilidade do paciente. Atravessando os riscos da identificação de discursos ainda sem lugar, o facilitador podia escutar a fenda das enunciações que viriam para subjetivar o espaço ocupado pela nomeação diagnóstica.

Por ser um campo de aprendizado e atuação dos residentes, o serviço organizou os pacientes em grupos de acordo com os seus diagnósticos psiquiátricos. No dia da semana do Grupo, a maioria dos pacientes havia recebido os diagnósticos de esquizofrenia, autismo e transtorno de humor, principalmente.

$\mathrm{O}$ formato de grupo aberto, realizado em um lugar de passagem (espécie de corredor) constituiu um lugar onde essas diversas vozes puderam circular/ transitar. Tal formato possibilitou, ainda, observar a dinâmica da relação mãe/ filho. Foi possível, por exemplo, ver algumas mães falarem de seus filhos como se eles não estivessem sentados ao lado (quando era o caso); presenciar um filho que entrava no grupo beijar a boca da mãe, ou testemunhar um adolescente que liderava a pauta do grupo com um relato de sua experiência.

Ao trabalhar com a metodologia de escuta de pais em grupo, Merletti (2015) refere-se à produção, nesse dispositivo, de pontos nodais veiculados nas falas dos pais que configuram significantes importantes da criança em tratamento. Foram encontrados nas sessões esses pontos nodais, inicialmente, como certezas estanques a respeito do que se sabia e se esperava do filho. A título de exemplo, é possível citar: "minha filha tem 15 anos, mas ela é uma criança" (fala a mãe de uma paciente que está se maquiando, sentada no sofá ao lado do grupo). Do mesmo modo, uma mãe cujos dois filhos são atendidos pelo serviço comenta sobre o mais novo deles, de maneira desolada: "vai ser igualzinho ao outro". Foi testemunhado também o discurso de uma mãe que diz saber que o destino do filho "se um dia ele casar, eu já sei que vão morar na minha casa, porque só eu sei cuidar dele".

Nesse grupo, onde as temáticas são espontâneas e variadas, existem algumas que retornam frequentemente, a saber: a escolarização da criança, a sexualidade, o sofrimento frente à sobrecarga dos cuidados, o medo de não 


\section{ARTIGOS}

suportar e enlouquecer, a loucura do(a) filho(a) e o preconceito. Os exemplos mostram a sedimentação de interpretações fixadas por discursos e diagnósticos que circulam, incidindo sobre os modos de filiação.

Um traço em comum perpassa as falas dos cuidadores: a angústia relacionada ao fantasma da imprevisibilidade das crianças em seus atos; o filho revelando-se outro em sua agressividade. Vejamos a seguir uma vinheta clínica breve.

\section{O que pode uma criança? Dênis e seu golpe de mestre}

O Grupo de Pais já havia começado, quando Dênis, ${ }^{3} 12$ anos, resolveu sentar-se ao lado da mãe. Foi-lhe dito que ali era um grupo para os pais e perguntado se ele gostaria de permanecer naquele dia. Ele decidiu permanecer, quando surgiu a temática de quanto os filhos exigem tempo das mães. Muitas relataram que os filhos passavam a maior parte do tempo em casa, sob seus cuidados. Os facilitadores perguntaram, então, sobre a possibilidade de introduzir outras atividades, externas ao convívio familiar, para as crianças e adolescentes.

Uma das mães expressou que havia retirado o filho do futebol por ter chutado muito forte um colega no jogo: "ele é muito grande, ai todo mundo tem medo dele. Aí ele só fica em casa mesmo". Outra relatou que já havia pensado em matricular o filho em uma escola de karatê, mas que ficara receosa: "o menino já é violento, se colocar pra lutar vai ficar mais ainda. Violência com violência não dá certo". Muitas mães falavam a respeito do quanto se dedicavam aos cuidados dos filhos, esquecendo-se até de si mesmas: "as consultas da minha filha eu não esqueço nenhuma; já as minhas esqueço sempre". Nesse momento, Dênis pediu licença para falar. Disse que era praticante de judô, que já havia participado de vários campeonatos, inclusive ganhado medalhas.

Dênis evocou sua habilidade e interesse pelas artes marciais, indicando a possibilidade da realização de atividades externas ao convívio familiar. As falas rapidamente retornaram para o medo da imprevisibilidade dos atos violentos dos filhos. No momento em que imperavam as falas sobre o receio de o esporte incentivar a agressividade, Dênis interveio, relatando: "meu mestre

${ }^{3} \mathrm{O}$ nome é fictício. 


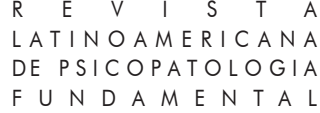

diz 'aqui, lutamos, mas, fora do tatame, somos amigos"'. Nesse momento, uma participante questionou a mãe de Dênis sobre os benefícios do esporte para o filho dela. A resposta foi simples e rápida: "Ele não melhorou nem piorou".

Dênis retomou a palavra mencionando suas medalhas e evoluções no esporte. Mais uma vez, ele parecia tentar responder, à sua maneira, sobre o benefício pessoal que o esporte trouxe. No meio da fala de Dênis, o psiquiatra do garoto os chamou (a ele e sua mãe) para a consulta. A mãe levantou-se imediatamente, mas Dênis disse que iria ficar ainda um pouco e que depois encontraria a mãe na consulta. Ao término de sua fala, Dênis queria ensinar um golpe. As pessoas do Grupo ficaram apreensivas, mas a segurança dos facilitadores em autorizá-lo acalma as mães. O garoto encena etapas da condução de uma aula de judô, em que realiza uma espécie de meditação e, em seguida, solicita autorização a um dos facilitadores para demonstrar um golpe e finaliza com o gesto de agradecimento do judô. Sua atuação, portanto, provém de um contexto de atividades estruturadas por um mestre que parece ter ensejado a Dênis uma possibilidade de inclusão. Tudo indica que, se para as mães, o único polo transferencial possível é a medicalização, para Dênis a transferência com o mestre do judô aponta para outras formas possíveis de reconhecimento.

As seis mães testemunharam suas dificuldades de colocar o filho numa atividade sem a prescrição médica. A discussão central da sessão de grupo relatada gravitou ao redor dos limites do que um sujeito, tendo recebido um diagnóstico psicopatológico de esquizofrenia, é capaz de fazer. No exemplo, a arte marcial, que utiliza golpes de socos e chutes, quando a criança já denota comportamentos agressivos, mostrou ser uma atividade comum à idade daquele garoto.

A pergunta de uma das mães, a respeito de como o esporte - mas pensamos que poderia ser qualquer outra atividade - pode ter melhorado o comportamento de Dênis, pode revelar a complexidade de se refletir sobre um futuro outro para aqueles jovens e crianças classificados e imobilizados pela prescrição médica. A resposta da mãe de Dênis: — "ele não melhorou, nem piorou" - pode demonstrar, por sua vez, que existe algo do desejo do filho que pertence a uma escolha pessoal. Um lutador que precisa obedecer a regras descritas pelo mestre e que pode, com suporte no seu desempenho, ganhar medalhas. O grande "golpe de mestre" de Dênis foi mostrar para as mães do grupo um talento seu, singular, independente do diagnóstico a ele atribuído. As mães, ainda tomadas pela expectativa de terem uma cena de violência explicita característica do quadro, pareceram nocauteadas pela coerência do discurso e dos movimentos do garoto. Outro "golpe de mestre" foi dado, 


\section{ARTIGOS}

fazendo valer seu importante papel na direção de seu tratamento e de sua vida, afirmando outras possibilidades de apropriação de um lugar de pertença, ali onde ele se sentia autorizado para agir e pensar diferente.

\section{Nomeação: filiação e diagnóstico}

Mannoni (1999), retomando Freud, indica que a sociedade confere à criança um estatuto, já que a encarrega de realizar o futuro do adulto, reparar o fracasso dos pais e mesmo realizar sonhos perdidos. Quando o caso, porém, é de crianças diagnosticadas com alguma psicopatologia, o que esperar delas? $\mathrm{Ou}$, como diz Vorcaro (2011), "quem é esse ser que deveria reconhecer a possibilidade de realizar nosso ideal?" (p. 221). Com amparo nesse questionamento, ela evoca os danos e sofrimentos da criança cujos pais não se reconhecem nela; danos motores, comportamentais, que podem inclusive remeter a fragilidades neurológicas.

Aqui chegamos ao âmbito principal: a nomeação está no cerne da operação de filiação. O filho, cuja origem está situada na cadeia significante que articula o desejo de seus antecessores, pertence a uma série em que o nome próprio o inscreve. Assim, a operação dá-se no deslocamento do ato sexual de fecundação para o reconhecimento do filho no registro simbólico (Jerusalinsky, 2011).

$\mathrm{Na}$ medida em que o social se ergue sobre a política como representante dos interesses da família, as instituições sociais, nas quais se inscreve o discurso médico, passam, então, a se considerar responsáveis pela ordem da parentalidade. As relações entre pais e filhos são também de sua competência.

Sob a justificativa da salvaguarda dos interesses da criança, foram produzidos, nos dois últimos séculos, idealizações em torno da infância e do corpo materno tomados inicialmente como território sagrado, "um paraíso originário que se deve perder, por certo, mas cuja experiência inapagável dá ao adulto equilíbrio e estabilidade" (Julien, 2000, p. 15). A valorização da infância e o paradigma da família afetiva são contemporâneos do maior controle de natalidade, com amplo acesso aos métodos contraceptivos, e incumbe os pais de um sentido de dever e de responsabilidade pessoal pelas crianças com a valorização da amamentação e a desconfiança em relação a amas de leite (Roudinesco, 2003).

Foi no decorrer do século XX que emergiu a crença de que, para melhor proteger esse paraíso, seria necessário fazer intervir o terceiro social. Esse foi o lugar ocupado por professores, psicólogos, pedopsiquiatras, pediatras, 
juízes, entre outros, asseguradores da lei do bem-estar que deve ser transmitida aos filhos, contando, desde já, com uma falência do parental para fazê-la valer integralmente.

Freud (1897/1996a) considerava o mito de Édipo um acontecimento universal na tenra infância, tributário dos sentimentos de amor e ódio dirigidos às figuras parentais. Em sua obra "Totem e tabu", Freud (1913/ 1996c) reforçou essa circunstância para a fundação do laço social. No mito da horda primitiva, ele pensou em um pai que atraía para si uma reunião de sentimentos de amor, ódio, inveja e admiração, sendo devorado e incorporado pelo grupo de irmãos. Logo depois do golpe ao pai, foi necessário anular os precedentes do ato, instituindo-se a Lei do Totem. Assim, só depois de morto, após instaurar o sentimento de culpa e tornar-se o sustentáculo da lei, o pai existe verdadeiramente como tal. O pai mítico, fonte de todo amor e ódio, deve dar lugar ao pai que, em tempos de democracia, não controla tudo, mas ocupa um lugar muito específico na família.

Em "À guisa de introdução ao narcisismo", Freud (1914/2004), enfim, está com estes três agentes no palco que a modernidade montou: a criança idealizada, o pai morto, a mulher para além da função materna. Por isso, há no seio do paradigma freudiano uma leitura sobre a mutação da sociedade e a conquista da subjetividade pela qual os agentes da sua trama familiar devem se individualizar. Curiosamente, é no conceito de narcisismo que as pretensões individualizantes esbarram. Do personagem grego ao conceito psicanalítico há uma diferença entre o condenado à paixão de si mesmo e o sentenciado a reencontrar no Outro o suporte de seu desamparo.

Não deve ter sido por acaso que Freud escreveu "À guisa de introdução ao narcisismo" (1914/2004) logo depois de produzir a obra "Totem e tabu" (1913/1996c). Que relações podemos encontrar entre o assassinato do pai e a criança que vem a ser um prolongamento dos pais? É certo que, tão logo os terceiros sociais, entre eles psicanalistas, médicos e professores, são convocados a corrigir as anomalias da parentalidade, garantindo a preservação do futuro das crianças, fica em evidência o que se banalizou como carência paterna.

A banalização da figura do pai exigiu um esforço de Lacan para reconstituir o seu lugar e a estratégia de revisita da teoria da nomeação. Mais atual ainda do que a separação do conjugal-parental é a dissociação da geração como evento biológico no concernente à nomeação. Lacan (19561957/1995; 1957-1958/1999) considerou a disjunção pai que cede o esperma e pai simbólico, cuja única função é transmitir um nome; um nome que tenha um valor de metáfora. A metáfora, como operação linguística, efetua uma 


\section{ARTIGOS}

substituição entre termos, ao passo que o trabalho específico da metáfora paterna é permitir que o Nome-do-Pai possa representar, logo, substituir uma ausência fundamental ante o desejo materno.

A função nomeante do pai está relacionada, também, com sua capacidade de articular lei e desejo. Uma vez instaurada a metáfora paterna, algo advém sobre o rumo que se dá ao desejo, ele tornando-se totalmente vinculado à sua interdição. Desse modo, a função do pai não é apenas garantir a permanência de uma lei imutável, de uma tradição, ainda que se advogue a importância desta como um dos princípios ordenadores da razão perante a parcialidade das pulsões. O Nome-do-Pai é, também, uma saída para o desejo e um suporte para que um significante do próprio sujeito venha posteriormente dialetizar a lei. Salienta-se isso para diferenciar a teoria psicanalítica sobre a filiação de uma tendência conservadora que se tornaria prescritiva e também moral.

A metáfora paterna é a condição para que a filiação mantenha um horizonte aberto, por onde um significante da criança possa existir. Ela é a promessa de que todas as significações caminham para a dissolução a fim de permitir o advento de um sujeito radicalmente novo (Didier-Weill, 1999). Se é inevitável que o narcisismo nos pais tente condensar todos os seus filhos dentro de um limite de expectativas, comumente relacionadas aos seus prazeres e modos de ver o mundo, também é indispensável que persista, em cada família, o desejo de ser ultrapassada por algo novo, o resultado do que ora chamamos de filiação pela via da metáfora paterna.

O sujeito constitui seu fantasma com arrimo na demanda do Outro, que vem na ordem da filiação como a posição em que o sujeito é situado na série familiar. Quando o diagnóstico vem para aplacar as buscas e as demandas dessas mães por saber "o que os filhos têm", a nomeação diagnóstica, que dá nome ao que causa estranhamento, pode sobredeterminar a nomeação simbólica, que se efetua desde o nome próprio. A repercussão é expressa como dificuldades de inserir o filho em uma operação simbólica de filiação, restringindo-a ao caráter imaginário das prescrições terapêuticas, no qual pode ocorrer uma espécie de permissão para que a ordem fechada do especialista obture a constituição de uma ordem aberta de significância.

Cabe ressaltar que a solidão a marcar a trajetória de vida de muitas dessas mães antecede o nascimento das crianças. Outras vezes, as mães são "abandonadas" por seus companheiros, tão logo os desafios com a criança se instauram. Algumas dessas crianças já foram ejetadas da escola, outras são negadas nas próprias famílias. Com efeito, o diagnóstico é o nome que precisavam para inserir a criança numa rede de cuidados. Nessas circunstâncias, 


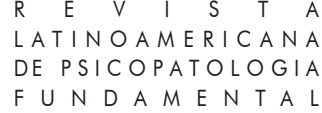

todavia, é válido fundamentar outro tipo de imposição que representa a suspensão das garantias de um estado de direito, em que deveriam vigorar os princípios da singularidade e da diferença. $\mathrm{O}$ deslize desse princípio caracteriza-se pela aliança entre a angústia e a disponibilidade irrestrita da mãe e o furor "medicalizante" e normativo do especialista que, por sua vez, também demanda reconhecimento de seu poder (Merhy, Feuerwerker \& Cerqueira Gomes, 2010). O especialista se firma em sua convocatória "medicalizante" e o diagnóstico opera como nomeação prescritiva na filiação.

É comum a queixa das mães e dos profissionais quanto à não adesão dos pais ao tratamento das crianças: "o pai não dá o remédio", "quando ele vai para a casa do pai, piora", "o pai não acredita na doença do filho", "pai só atrapalha" - são falas que funcionam como pontos de amarração das dificuldades identificatórias dentro do grupo. Como escutar esses enunciados? Nas entrelinhas dessa queixa aos pais que não cumprem prescrições, revela-se, ainda, um dos exercícios da função materna e sua aliança com os discursos normativos. A nomeação diagnóstica tem, entre outros efeitos, o de apaziguar a angústia materna. Do lado da criança, o diagnóstico pode vir a impedir os devires abertos de uma função metafórica que advém da sua filiação. Neste caso, o golpe do mestre é questionador do saber que se perfaz também do lado da criança acerca de seu sofrimento.

No caso de Dênis, o 'seu mestre' inaugura outra forma de convocatória; e seu golpe de mestre é o de romper com essa restrição prescritiva, negando-se, na reunião, a interromper seu ato simbólico metaforizado no jogo ante a convocatória do médico. Finalizar sua apresentação no grupo significou situar-se desde seu próprio nome.

\section{Considerações finais}

A investigação sobre a repercussão do enunciado de um diagnóstico psicopatológico para crianças e adolescentes com trajetória de vida marcada pela institucionalização do cuidado mostra efeitos no estabelecimento da filiação. Em muitos casos, o diagnóstico foi visto como vetor de nomeação da criança, aplacando a angústia dos pais frente ao que comparece como estranho no comportamento dos filhos. Todavia, é importante apontar os riscos e limites de uma filiação proveniente de uma adesão ao saber classificatório dos Manuais. O trabalho com os pais e a escuta da criança fazem-se imprescindíveis na direção do tratamento. Acolher as angústias do "não saber" e dar suporte a um saber 


\section{ARTIGOS}

autêntico que os pais possuem sobre seus filhos revelam-se estratégias clínicas necessárias. Como afirma Kupfer (2011), "para a psicanálise, tratar é recuperar o sentido das produções das crianças, é reconstruir ou construir o percurso do sujeito, é buscar recuperar o saber inconsciente dos pais" (p. 148).

A criação de um Manual, com sintomas descritos e catalogados em nomenclaturas psiquiátricas, objetivou estabelecer uma linguagem universal para o diálogo entre os médicos e outros profissionais da saúde. Perceptível, no entanto, é um deslocamento dessas nomenclaturas para o senso comum. $\mathrm{O}$ que se reserva para o futuro daquele sujeito psiquiatricamente diagnosticado, quando, inclusive, os pais se propõem a tratá-lo e cuidá-lo segundo expectativas definidas e definitivas?

A suposição simbólica do sujeito é o que possibilita sua emergência como tal. Essas marcas são determinantes, na medida em que é necessário haver fundações para que qualquer construção possa ser assentada. O alicerce, entretanto, é apenas o início de uma construção. Considerando-se que o sujeito se constitui entre o movimento metonímico do desejo e a fixação em ficções identificatórias, é possível pensar que nos seus deslocamentos, suas errâncias, pode estabelecer uma abertura a outras posições, construindo novas ficções de si (Rosa et al., 2007). Em outras palavras, deslocar-se do fixar para o ficcionar. O diagnóstico e o caráter prescritivo que incidem nas relações de filiação podem operar como fixação, dificultando as possibilidades de ficção e os deslocamentos perante o mal-estar particular a cada sujeito. Dênis, com sua intervenção no Grupo, abriu espaço para se pensar o que pode uma criança frente a essas questões.

\section{Referências}

Coriat, E. (2011). Os negros efeitos do DSM-IV. In A. Jerusalinsky, \& S. Fendrik (Orgs.), O livro negro da psicopatologia contemporânea (pp. 165-174). São Paulo: Via Lettera.

Didier-Weill, A. (1999). Invocações: Dionísio, Moisés, São Paulo e Freud. Rio de

Janeiro: Cia. de Freud.

Dunker, C. (2015). Mal-estar, sofrimento e sintoma: uma psicopatologia do Brasil entre muros. São Paulo: Boitempo.

Fórum Sobre Medicalização da Educação e Saúde (2015). Recomendações de práticas não medicalizantes para profissionais e serviços de educação e saúde. São Paulo: Conselho Federal de Psicologia. 
Freud, S. (1996a). Carta 71. In Edição Standard Brasileira das Obras Psicológicas Completas de Sigmund Freud (J. Salomão, trad., Vol. 1, pp. 314-317). Rio de Janeiro: Imago. (Trabalho original publicado em 1897).

Freud, S. (1996b). Moral sexual civilizada e doença nervosa moderna. In Edição Standard Brasileira das Obras Psicológicas Completas de Sigmund Freud (J. Salomão, trad., Vol. 9, pp. 167-186). Rio de Janeiro: Imago. (Trabalho original publicado em 1908).

Freud, S. (1996c). Totem e tabu. In Obras psicológicas completas de Sigmund Freud (J. Salomão, trad., Vol. 13, pp.12-163). Rio de Janeiro: Imago. (Trabalho original publicado em 1913).

Freud, S. (1996d). O mal-estar na civilização. In Edição Standard Brasileira das Obras Psicológicas Completas de Sigmund Freud (J. Salomão, trad., Vol. 21, pp. 65-148). Rio de Janeiro: Imago. (Trabalho original publicado em 1930).

Freud, S. (2004). À guisa de introdução ao narcisismo. In Obras psicológicas de Sigmund Freud: escritos sobre a psicologia do inconsciente (L. A. Hanns, trad., Vol. 1, pp. 95-131). Rio de Janeiro: Imago. (Trabalho original publicado em 1914).

Jerusalinsky, A. (2011). Para compreender a criança: chaves psicanalíticas. São Paulo: Instituto Langage.

Julien, P. (2000). Abandonarás teu pai e tua mãe. Rio de Janeiro: Cia. de Freud.

Kupfer, M. C. (2011). Educação terapêutica para crianças com Transtornos Globais do Desenvolvimento: uma alternativa à medicalização da educação. In A. Jerusalinsky, \& S. Fendrik (Orgs.), O livro negro da psicopatologia contemporânea (pp.141-150). São Paulo: Via Lettera.

Lacan, J. (1995). O seminário. Livro 4. A relação de objeto. Rio de Janeiro: Jorge Zahar. (Trabalho original publicado em 1956-1957).

Lacan, J. (1999). O seminário. Livro 5. As formações do inconsciente. Rio de Janeiro: Jorge Zahar. (Trabalho original publicado em 1957-1958).

Mannoni, M. (1999). A criança, sua "doença" e os outros. São Paulo: Via Lettera.

Merhy, E., Feuerwerker, L., \& Cerqueira Gomes, M. (2010). Da repetição à diferença: construindo sentidos com o outro no mundo do cuidado. In T. Franco, \& V. Ramos (Orgs.), Semiótica, afecção e cuidado em saúde (pp. 60-75). São Paulo: Hucitec.

Merletti, C. (2015). Escuta psicanalítica de pais em âmbito grupal: diferentes posições discursivas e seus efeitos para a criança autista. In A. Jerusalinsky (Org.), Dossiê Autismo (pp. 234-249). São Paulo: Instituto Langage.

Porge, E. (2015). As vozes, a voz. In M. E. Maliska (Org.), A voz na psicanálise: suas incidências na constituição do sujeito. Curitiba: Juruá.

Roudinesco, E. (2003). A família em desordem. Rio de Janeiro: Zahar. 


\section{ARTIGOS}

Rosa, M. D., Carignato, T., \& Berta, S. (2007). Metáforas do deslocamento: imigrantes, migrantes e refugiados e a condição errante do desejo. In A. Costa, \& D. Rinaldi (Orgs.), Escrita e psicanálise (pp. 371-387). Rio de Janeiro: Cia. de Freud.

Travaglia, A. (2014). Psicanálise e saúde mental, uma visão crítica sobre psicopatologia contemporânea e a questão dos diagnósticos. Psicologia Revista. 23(1), 31-49. Recuperado de <http://revistas.pucsp.br/index.php/psicorevista/ article/viewFile/20213/15042>.

Vorcaro, A. (2011). O efeito bumerangue da classificação psicopatológica da infância. In A. Jerusalinsky, \& S. Fendrik (Orgs.). O livro negro da psicopatologia contemporânea (pp. 219-229). São Paulo: Via Lettera

\section{Resumos}

(A masterstroke: Children and parents in face of psychiatric diagnosis)

This study is based on the reflections arising from listening and intervening in a group of parents in a public psychiatric clinic. The dichotomy of the effects of diagnostic nomination seems sometimes to allow children and adolescents to be enrolled in an order of parentage, and sometimes to render the possibilities of subjectification inflexible. We discuss the forms of parentage built under the prescriptive character of the psychiatric diagnosis and their possible effects on the manners of caring and the bonds between parents and children.

Key words: Diagnosis, nomination, parentage, psychoanalysis with children

(Un coup de maître: enfants et parents face au diagnostic psychiatrique)

Cet article présente un ensemble de réflexions survenues lors d'un travail d'écoute et d'intervention au sein d'un groupe parents d'un service psychiatrique. La dichotomie des effets de l'énoncé d'un diagnostic psychiatrique peut se manifester d'une part à travers l'inscription de l'enfant/l'adolescent dans un ordre de filiation, d'autre part en réduisant ses possibilités de subjectivation. Cet article propose questionner les formes de filiations construites à partir des critères prescriptifs du diagnostic et ses effets possibles sur les soins et sur les liens parent-enfant.

Mots-clés: Diagnostic, nomination, filiation, psychanalyse d'enfants

(Un golpe de maestro: padres y niños frente al diagnóstico psiquiátrico)

El presente trabajo proviene de reflexiones que surgen de la escucha y la intervención en un grupo de padres, realizado en un ambulatorio psiquiátrico público. La dicotomía de los efectos del nombramiento diagnóstico se presenta, unas veces, 


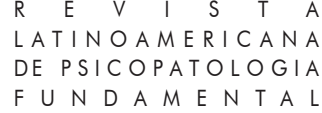

permitiendo la inscripción del niño y del adolescente en una orden de filiación $y$, otras veces, produciendo una fijación de las posibilidades de subjetivación. Se problematizan las formas de filiación construidas bajo el carácter prescriptivo del diagnóstico psiquiátrico y sus posibles efectos en los modos de cuidar y en los lazos establecidos entre padres e hijos.

Palabras clave: Diagnóstico, nombramiento, filiación, psicoanálisis con niños

(Geniestreich: Kinder und Eltern die mit psychiatrischen Diagnosen konfrontiert werden)

Der vorliegende Artikel ist das Ergebnis einer Reihe von Überlegungen basierend auf Aussagen einer Elterngruppe einer psychiatrischen Tagesklinik. Die Dichotomie der Auswirkungen der Diagnosis manifestiert sich entweder indem sie es dem Kind/Jugendlichen erlaubt, in eine erbliche Ordnung einzugehen, oder indem sie die Möglichkeiten der Subjektivierung erstarren lässt. Der Artikel diskutiert weiter die Formen der Filiation welche aufgrund der präskriptiven Eigenschaft der psychiatrischen Diagnose entstehen, sowie die möglichen Auswirkungen auf die verschiedenen Pflegearten und auf die Eltern-Kind-Beziehung.

Schlüsselwörter: Diagnose, Nominierung, Filiation, Psychoanalyse des Krindes

(绝妙的打击: 精神病学诊断中的孩子与父母关系)

本论文对一个公立精神病诊所的工作结果进行研究, 并反思这个诊 所对父母群体所做的倾听与心理干预。我们发现精神病诊所的指称性诊 断 (nomeação diagnóstica) 有双重性, 它一方面允许儿童和青少年进入 父母-子女的等级关系, 另一方面, 它固化儿童与青少年的主体性的发 展。我们讨论精神病学诊断机构所构建的父子关系模式, 以及此模式对 父母与孩子间所建立的关系可能产生的负面影响。

关键词：诊断，指称 (nomeação), 子女身份, 儿童精神分析。

Citação/Citation: Martins, K. P. H. et al. (2017, junho). Um golpe de mestre: crianças e pais frente ao diagnóstico psiquiátrico. Revista Latinoamericana de Psicopatologia Fundamental, 20(2), 278-293. http://dx.doi.org/10.1590/1415-4714.2017v20n2p278.5

Editores do artigo/Editors: Profa. Dra. Ana Maria Rudge e Profa. Dra. Sonia Leite

Recebido/Received: 25.9.2016 / 9.25.2015 Aceito/Accepted: 19.11.2016 / 11.19.2016

Copyright: (C) 2009 Associação Universitária de Pesquisa em Psicopatologia Fundamental/ University Association for Research in Fundamental Psychopathology. Este é um artigo de livre acesso, que permite uso irrestrito, distribuição e reprodução em qualquer meio, desde 


\section{ARTIGOS}

que o autor e a fonte sejam citados / This is an open-access article, which permits unrestricted use, distribution, and reproduction in any medium, provided the original authors and sources are credited.

Financiamento/Funding: Os autores declaram não ter sido apoiados ou financiados / The authors have no support or funding to report.

Conflito de interesses/Conflict of interest: Os autores declaram que não há conflito de interesses / The authors have no conflict of interest to declare.

\section{Karla Patrícia Holanda Martins}

Psicanalista; Professora adjunta da Universidade Federal do Ceará - UFC (Fortaleza, CE, Br); Pós-doutoranda do Instituto de Psicologia da USP (São Paulo, SP, Br); Bolsista de Pós-doutorado Sênior do CNPq.

Avenida da Universidade 2762 - Benfica

60020-180 Fortaleza, CE, Br.

kphm@uol.com.br.

\section{Raquel Alencar Barreira Rolim}

Doutora em Psicopatologia e Psicanálise pela Université Paris 7- Denis Diderot (Paris, França); Bolsista DCR CNPq/FUNCAP no Departamento de Pós-graduação da Universidade Federal do Ceará - UFC (Fortaleza, CE, Br).

Avenida da Universidade, 2762 - Benfica

60020-180 Fortaleza, CE, Br.

raquelbarreira@hotmail.com

\section{Gabriela Monteiro Simão}

Psicanalista; Mestranda em Psicologia pela Universidade Federal do Ceará - UFC (Fortaleza, CE, Br); Bolsista de Mestrado da Funcap; Membro do Fórum do Campo Lacaniano de Fortaleza.

Avenida da Universidade, 2762 - Benfica

60020-180 Fortaleza, CE, Br.

gabrielamsimao@gmail.com

Paulo Alves Parente Júnior

Mestrando em Psicologia pela Universidade Federal do Ceará - UFC (Fortaleza, CE, Br); Bolsista de Mestrado da CAPES.

Avenida da Universidade, 2762 - Benfica

60020-180 Fortaleza, CE, Br.

papj.33@gmail.com.

This is an open-access article, which permits unrestricted use, distribution,

(cC) BY-NC and reproduction in any medium for non-commercial purposes provided the original authors and sources are credited. 